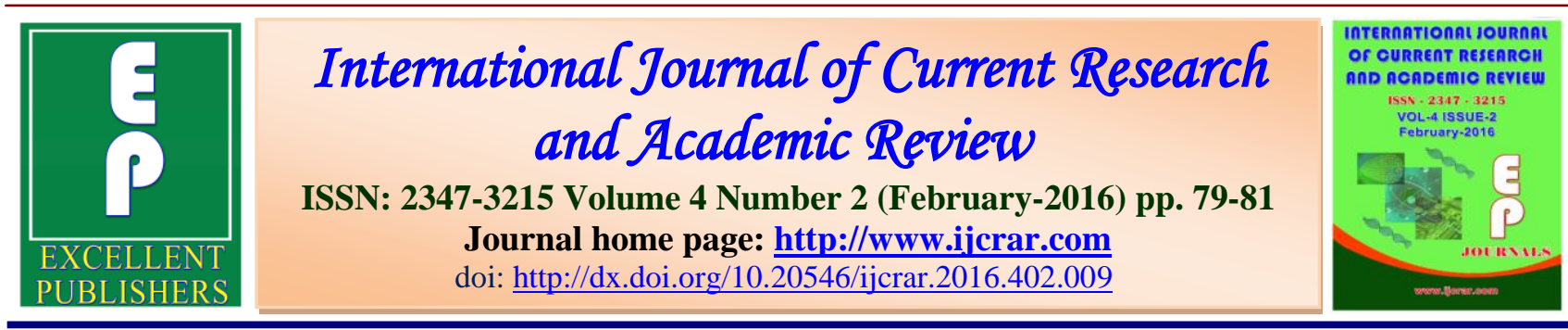

\title{
Disseminated Cysticercosis along with Multiple Ring Lesion in MRI:
}

\section{Case Report}

Samia Kirmani ${ }^{1}$, Haris Manzoor Khan ${ }^{1}$, Urfi $^{2}$ and Mohd. Khalid ${ }^{3}$

${ }^{1}$ Department of Microbiology, Jawaharlal Nehru Medical College, Aligarh Muslim University (AMU), Aligarh, U.P., India

${ }^{2}$ Department of Community Medicine, Jawaharlal Nehru Medical College, Aligarh Muslim University (AMU), Aligarh, U.P., India

${ }^{3}$ Department of Radiodiagnosis, Jawaharlal Nehru Medical College, Aligarh Muslim University (AMU), Aligarh, U.P., India

*Corresponding author

\section{KEYWORDS}

Seizures;

Neurocysticercosis;

Taeniasolium

\section{A B S T R A C T}

Cysticercosis is one of the tropical diseases. Neurocysticercosis is one of the most common parasitic infection affecting the central nervous system and an important cause of seizures in developing countries like India.Single ring enhancing lesion is the commonest finding on MRI. We describe acase report of a 31 years old young male who presented with seizures and severe headache to medicine OPD and was found to have muliple lesion neurocysticercosis on radioimaging along with lesions in orbit and parotid gland.

\section{Introduction}

Cysticercosisis caused by larval forms of the tapeworm Taeniasolium. It is an important cause of seizures in India. Single lesion nerocysticercosis is more common compared to multiple lesion. We come across a 31 year old male patient with multiple lesion found on MRI.

The aim of this report is to increase the awareness about the possibility of disseminated cysticercosis among patients with headache\& to report this rare case.

\section{Case Report}

A 31-year-old male patient presented in to medicine OPD with complains of seizures and severe headache for the past 1 month along with vomiting with 2-3 episodes per day. There was no history of vision problem or skin nodules. No history of fever, cough, chest pain, shortness of breath, palpitation, loss of appetite or weight loss. MRI showed multiple scattered ring enhancing lesions in the brain parenchyma indicative of NCC 
along with a cyst in parotid \& intraorbital region.

Clinical presentation of NCC depends on:

(i)location, growth, size and number of cyst

(ii)the stage of cyst - vesicular, degenerative, calcific; and

(iii)immune response of the host

Management was done by systemic steroids and albendazole. On follow up, improvement in the symptoms was found.

\section{Results and Discussion}

We described a case of 31 year old male patient who presented with seizures \& headache and after radioimaging was found to have multiple lesion neurocysticercosis with lesions in parotid gland. Carpio (2013) also found seizures as the most common presentation in $79 \%$ cases. Del Brutto (2012) found seizures present in $73 \%$ of patients as the most common clinical manifestation of the disease.

Single lesion neurocysticercosis is more common (Patil and Paithankar, 2012; Gauchan et al., 2011). However we described a case of multiple ring lesion cysticercosis with dissemination to parotid gland and orbit. Yamasaki (2013) while studying epidemiology of cysticercosis in Japanreported51.9\% of patients having multiple lesions.

Figure.1 MRI Brain Showing Showing Multiple Lesion Cysticercosis

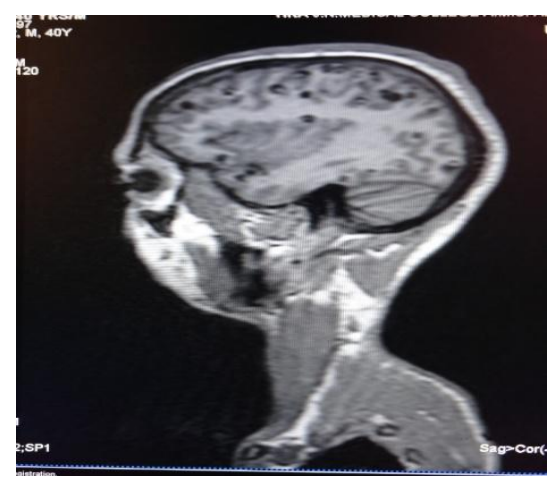

Figure.2 Mri Brain Showing Showing Multiple Lesions in Brain along with Lesions in Parotid Gland

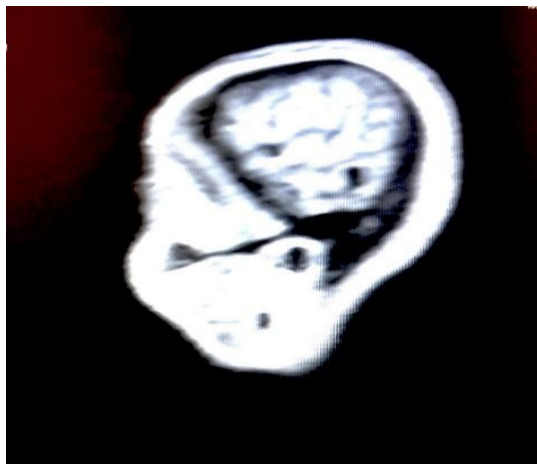


Figure.3 Axial Flair Image of Brain Showing Multiple Lesions Distributed Bilaterally

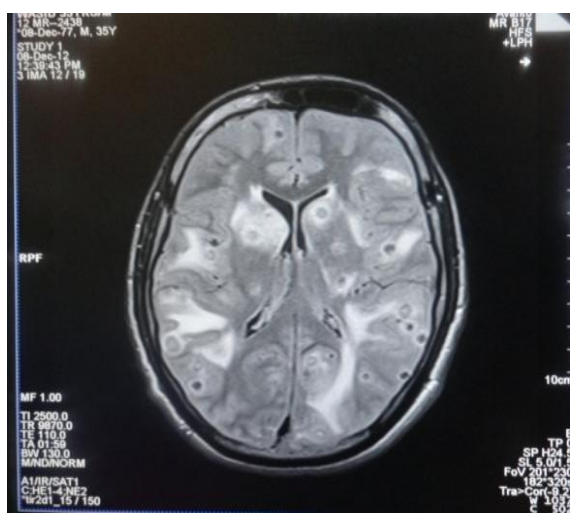

\section{Conclusion}

This case report emphasizes that disseminated cysticercosis although rare can be diagnosed easily on MRI and is easily treatable with very good chances of recovery.

\section{Conflict of interest}

There is no conflict of interest. There is no source of funding. The research article is neither published nor under consideration anywhere.

\section{References}

Carpio, A. 2013. Novel aspects on cysticercosis and neurocysticercosis: Clinical Diagnoses of Neurocysticercosis. 278-288.
Del Brutto, O.H. 2012. Neurocysticercosis among international travelers to disease-endemic areas.J Travel Med. 19(2): 112-117.

Patil, T.B., Paithankar, M.M. 2012.Clinicoradiological profile and treatment outcomes in neurocysticercosis: A study of 40 patients. Ann Trop Med Public Health. 5(2): 63-68.

Gauchan, E., Malla, T., Basnet, S., Rao, K.S. 2011.Variability of presentations and CT-scan findings in children with neurocysticercosis. Kathmandu Univ Med J. 9(34): 17-21.

Yamasaki, H. 2013. Current status and perspectives of cysticercosis and taeniasis in Japan. Korean J Parasitol. 51(1): 19-29.

\section{How to cite this article:}

Samia Kirmani, HarisManzoor Khan, Urfi and Mohd. Khalid. 2016. Disseminated Cysticercosis along with Multiple Ring Lesion in MRI: Case Report. Int.J.Curr.Res.Aca.Rev. 4(2): 79-81. doi: http://dx.doi.org/10.20546/ijcrar.2016.402.009 